\title{
BJO
}

\section{Clinical evaluation of the MacuScope macular pigment densitometer}

Hannah Bartlett, Jennifer Acton and Frank Eperjesi

Br J Ophthalmol 2010 94: 328-331 originally published online October 22, 2009

doi: 10.1136/bjo.2009.167213

Updated information and services can be found at:

http://bjo.bmj.com/content/94/3/328.full.html

These include:

References This article cites 25 articles, 14 of which can be accessed free at: http://bjo.bmj.com/content/94/3/328.full.html\#ref-list-1

Email alerting Receive free email alerts when new articles cite this article. Sign up in the service box at the top right corner of the online article.

\section{Notes}

To order reprints of this article go to:

http://bjo.bmj.com/cgi/reprintform

To subscribe to British Journal of Ophthalmology go to:

http://bjo.bmj.com/subscriptions 


\title{
Clinical evaluation of the MacuScope macular pigment densitometer
}

\author{
Hannah Bartlett, Jennifer Acton, Frank Eperjesi
}

Ophthalmic Research Group, School of Life and Health Sciences, Aston University, Birmingham, UK

\section{Correspondence to}

Dr Hannah Bartlett, Ophthalmic Research Group, School of Life and Health Sciences, Aston University, Birmingham B4 7ET, UK; H.E.Bartlett@aston.ac.uk

Accepted 5 October 2009 Published Online First 22 October 2009

\begin{abstract}
Background/aims The MacuScope uses

a psychophysical technique called heterochromic flicker photometry to measure macular pigment optical density (MPOD). Our aim was to determine the measurement variability (noise) of the MacuScope.

Methods Thirty-eight normally sighted participants who ranged in age from 19 to 46 years (25.7 \pm 7.6 years)

were recruited from staff and students of Aston University. Data were collected by two operators, HB and $\mathrm{JA}$, in two sessions separated by 1 week in order to assess test repeatability and reproducibility.

Results The overall mean MPOD for the cohort was $0.47 \pm 0.14$. There was a significant negative correlation between MacuScope MPOD readings and age $(r=-0.368, p=0.023)$. Coefficients were 0.45 and 0.58 for repeatability, and 0.49 and 0.36 for reproducibility. For each pair of results, there was a significant positive correlation between mean and difference MPOD values. Conclusions If MPOD is being monitored over time then any change less than 0.58 units should not be considered clinically significant as it is very likely to be due to instrument noise. The size of the coefficient appears to be positively correlated with MPOD.
\end{abstract}

\section{INTRODUCTION}

Yellow pigmentation of the macular region was first documented in 1782, and was attributed to the xanthophyll group of carotenoids much later in 1945. ${ }^{1}$ Two slightly different chemical structures have been found, termed lutein (L) and zeaxanthin (Z). ${ }^{2}$ It has been suggested that xanthophylls, in the form of macular pigment (MP) play a similar role in humans as in plants, as antioxidants and screeners of high-energy blue light. ${ }^{3}$ The presence of MP in the rod outer segments and retinal pigment epithelium $(\mathrm{RPE})^{4} 5$ is suggestive of a ROSquenching function and the presence of $\mathrm{MP}$ in the inner retinal layers ${ }^{6}$ supports a photoprotective role. The absorbance spectrum of MP peaks at $460 \mathrm{~nm}$ and it is purported to act as a broadband filter, reducing the sensitivity of the macular region to short wavelength light which is most damaging in the $440-460 \mathrm{~nm}$ range. ${ }^{78}$

The human retina, and more specifically the macula, is the single richest site of carotenoid accumulation within the human body. Post-mortem retinal analysis has shown that the total $\mathrm{L}$ and $\mathrm{Z}$ concentration at the macula is 100 times more than at the peripheral retina. The assumption that retinal $\mathrm{L}$ and $\mathrm{Z}$ is of dietary origin is supported by fundus photographs of rhesus monkeys on carotenoiddepleted diets that demonstrate an absence of MP. ${ }^{9}$

Recently, instruments have been developed for the measurement of MP optical density (MPOD) in the clinical environment. These instruments employ a psychophysical technique called heterochromatic flicker photometry (HFP). One of these instruments is the MacuScope macular pigment densitometer (Macuvision Europe Ltd, Solihull, UK). This is a portable desktop device that requires subjects to observe flickering stimuli that are comprised of two alternating wavelengths of light. One wavelength is absorbed by MP $(465 \mathrm{~nm})$ and one is not $(550 \mathrm{~nm})$. During the test, the luminance ratio of the two wavelengths is reduced until the flicker is minimised. This minimal flicker point is recorded by the instrument for one central (where MP is assumed to be maximal) and one peripheral (where MP is assumed to be minimal) location. The ratio of luminance values at these two locations is then used to calculate the final MPOD value.

It is important to determine the measurement variability, or measurement noise, of the MacuScope in order to be able to identify clinically significant changes in MPOD. This is of particular interest considering that the MacuScope might be considered for use in monitoring the effect of nutritional supplementation or dietary modification on MPOD. The aim of this study was to assess the repeatability and reproducibility of the MacuScope when used in a clinical setting.

\section{MATERIALS AND METHODS \\ Setting}

A clinical practice setting within the Ophthalmic Research Group, School of Life and Health Sciences at Aston University, Birmingham, UK.

\section{Study population}

Thirty-eight normally sighted participants were recruited from staff and students of Aston University. Participants varied in age from 19 to 46 years (25.7 \pm 7.6 years).

Exclusion criteria were: best corrected distance visual acuity (VA) of more than $0.2 \log$ MAR (VA was measured under standard testing conditions using a $\log$ MAR chart, retro illuminated to a luminance of $130 \mathrm{~cd} / \mathrm{m}^{2} 10$ (each letter seen was scored as $0.02 \log$ units, with guessing encouraged)); retinal disease detected through undilated pupils using a direct ophthalmoscope; abnormal Amsler grid test result; glaucoma; lenticular opacities; prescribed medication associated with changes in retinal function.

\section{Observation procedures}

The same testing room was used for each test for all data collection sessions. When both eyes met the inclusion criteria, the right eye was tested; when only one eye was suitable for inclusion, that eye 
was tested. The test was carried out according to the manufacturer's instructions.

The eye not being tested was occluded and subjects were asked to place their forehead in position such that the test eye was centred on a cross-hair target within the instrument. Adjustments were made by the operator until the subject reported the cross-hair target to be clearly in focus. Participants with astigmatic ametropia or high levels of spherical ametropia (> 7D) wore their habitual refractive correction. When the operator began the test the subject immediately observed the flickering stimulus, which was centred on the cross-hair target. Each subject was then asked to fixate the cross-hair target. The intensity of the flickering target was altered manually by the operator until the subject reported 'minimum' flicker. The process was repeated with each subject instructed to fixate a peripheral cross-hair target, and to observe the change in flicker of the central target using non-foveal retina. Once the point of minimum flicker is reached for central and peripheral stimuli, the instrument automatically calculates the MPOD for that eye and provides a print out of the result.

Data were collected by two operators, HB and JA, in two sessions separated by 1 week. Prior to the first session a trial run was completed to allow each participant to practice the test. For the purposes of the study, the operator LCD display of target intensity was covered to prevent operator bias of the results. In session one, the first test was carried out by JA (JA1) and the second was carried out by $\mathrm{HB}$ (HB1). In session two the first test was carried out by $\mathrm{HB}$ (HB2) and the second was carried out by JA (JA2). This study design permitted assessment of the test repeatability (HB1 vs HB2 and JA1 vs JA2) and reproducibility (JA1 vs HB1 and HB2 vs JA2). SPSS for Microsoft Windows XP software was used for data analysis. Graphs were produced using SigmaPlot software (version 6) for Microsoft Windows XP.

\section{RESULTS}

The four sets of readings (the practice reading was excluded) were averaged for each subject. The overall mean MPOD for the cohort was $0.47 \pm 0.14$. The mean individual SD value for the whole cohort (excluding the practice reading) was $0.15 \pm 0.011$. There was a significant negative correlation between MacuScope $M P O D$ readings and age $(\mathrm{r}=-0.368, \mathrm{p}=0.023)$. The mean MPOD reading for women $(n=18)$ was $0.49 \pm 0.17$ and for men $(n=20)$ was $0.45 \pm 0.11$. These mean values were not significantly different ( $t=0.612, p=0.545)$.

Accurate analysis of test - retest data can be achieved using the coefficient of repeatability. ${ }^{11} 12$ This gives the $95 \%$ confidence limits for the amount of difference between two sets of results. It is calculated as 1.96 multiplied by the SD of the mean differences between the two sets of data. Test-retest results for the four comparisons are shown in table 1.

The coefficient of repeatability and reproducibility values indicate the amount of change that can occur between readings and still be classed as instrument 'noise'. In other words, using the worst result of the two for repeatability, our data suggests

Table 1 Coefficient of repeatability/reproducibility values for the four data sets

\begin{tabular}{llllll}
\hline & \multicolumn{2}{l}{ Repeatability } & & \multicolumn{2}{l}{ Reproducibility } \\
\cline { 2 - 3 } \cline { 5 - 6 } & \multicolumn{2}{l}{ JA1-JA2 } & HB1-HB2 & & JA1-HB1 HB2-JA1 \\
\hline Mean difference & 0.019 & 0.031 & -0.095 & 0.082 \\
SD of mean differences & 0.23 & 0.30 & 0.25 & 0.18 \\
Coefficient of repeatability/ & 0.45 & 0.58 & 0.49 & 0.36 \\
reproducibility & & & & \\
\hline
\end{tabular}

that when the same operator is taking repeated MacuScope readings over time, only increases or decreases in MPOD of more than 0.58 units can be classed as clinically significant (see figure 1). Using the worst result of the two for reproducibility, if two different operators are assessing MPOD with the MacuScope within the same session, only increases or decreases in MPOD of more than 0.49 units can be classed as clinically significant (see figure 2).

For each pair of results, there was a significant positive correlation between mean and difference in MPOD values (JA1-JA2: $r=0.597, p<0.001$; HB1-HB2: $r=0.527, p=0.001$; JA1-HB1: $r=0.470, p=0.003$; HB2-JA2: $r=0.450 . p=0.005)$. In other words, the difference between two sets of readings increased as the MPOD increased. There was no correlation between the difference between readings represented as a percentage of the mean MPOD value and the mean MPOD value for all comparisons except JA1-JA2 $(r=0.402, p=0.014)$.

\section{DISCUSSION}

We consider our findings to be useful for eye care practitioners who use the MacuScope for monitoring of MPOD over time, or as an outcome measure to assess the effect of dietary modification or nutritional supplementation on MPOD. Several largescale studies have used HFP techniques for assessment of MPOD. ${ }^{13-18}$ Our average MPOD value was $0.47 \pm 0.14$. Other studies have reported average values in normal cohorts of $0.211 \pm 0.13$ ( $n=280$, age range: $18-50$ years), ${ }^{13} 0.28 \pm 0.21$ $(n=280$, age range: $18-50$ years $),{ }^{14} 0.289 \pm 0.156 \quad(n=46$, age range: $21-81$ years), ${ }^{19} 0.319$ ( $n=100$, age range: $22-60$ years), ${ }^{15}$ and $0.43 \pm 0.23$ ( $n=1648$, age range: $53-86$ years).$^{20}$

Within our cohort there was a significant negative correlation between MPOD reading and age. This relationship has also been investigated using HFP in other studies; some have reported a similar relationship, ${ }^{19} 21$ while others reported no relationship. $^{14} 2223$

Our reliability results differ markedly from those found by another group investigating the use of HFP who reported a coefficient of reproducibility of 0.08 and a coefficient of repeatability of $0.09 .{ }^{19}$ These differences might be explained by the fact that we used a commercially produced instrument rather than a laboratory-based instrument designed for research

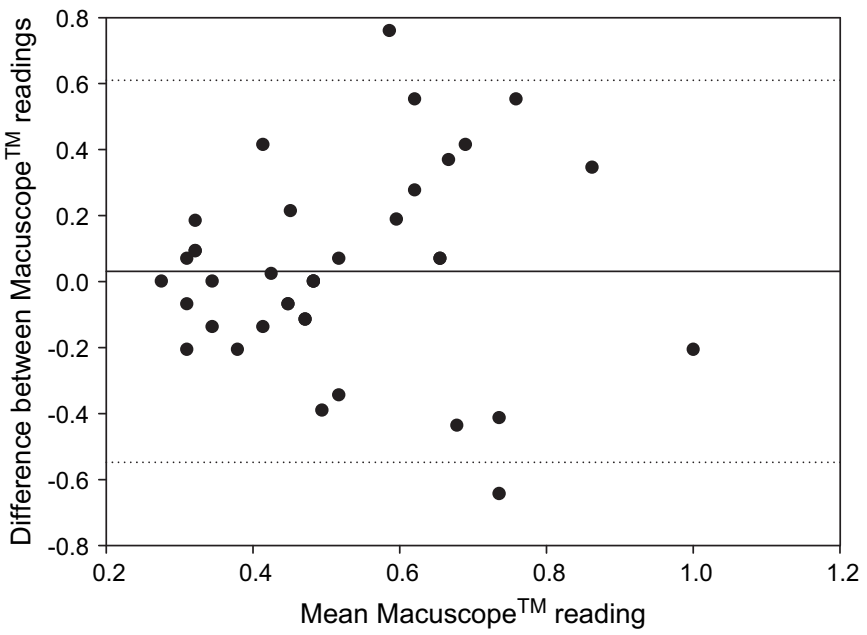

Figure 1 Difference in MacuScope reading between HB1 and HB2 compared with the mean $(n=38)$. The mean bias is represented by the solid line and the $95 \%$ confidence limits are represented by the dashed lines. 


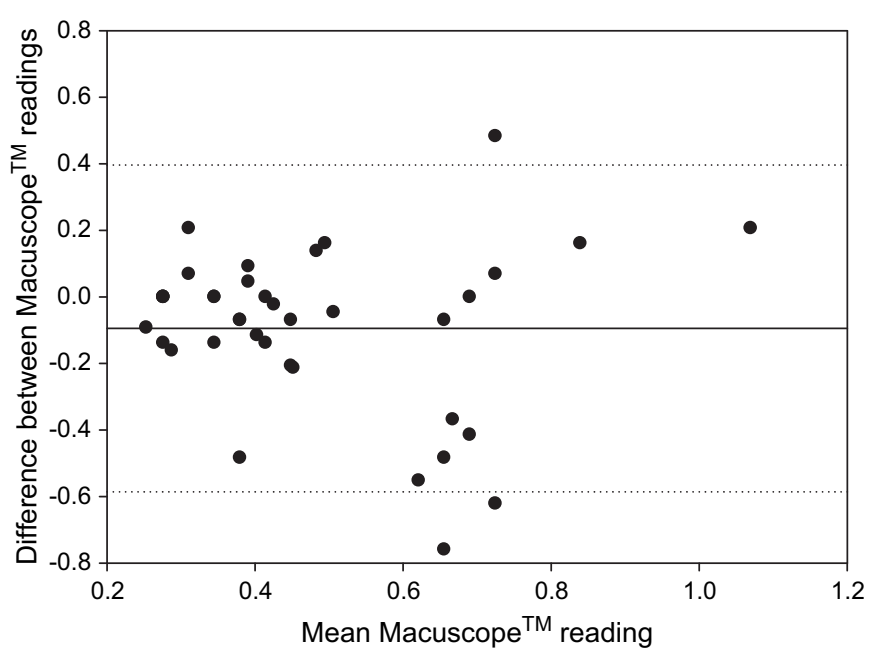

Figure 2 Difference in MacuScope reading between JA1 and HB1 compared with the mean $(n=38)$. The mean bias is represented by the solid line and the $95 \%$ confidence limits are represented by the dashed lines.

purposes. The authors of this study also state that they took five readings on two different occasions (although the method for assessing reliability was not made clear), and so comparing the means of repeated readings may have resulted in smaller reproducibility and repeatability coefficients. Our study protocol permitted a practice run of the test, which we considered to be reasonable considering that the instrument is designed to be used in a clinical environment; we were keen to assess the instrument in a way that would make the results applicable to the clinical setting. Our five sets of repeat data were not significantly different when analysed using ANOVA $(F=1.177, \mathrm{p}=0.322)$, suggesting no significant learning effect. We attribute our relatively large coefficients of repeatability and reproducibility to the fact that participants found the task conceptually difficult. The state of 'minimum flicker' is hard to describe (particularly to naïve subjects) and harder to identify. Participants reported that trying to identify the central minimum flicker point whilst fixating on the peripheral target was particularly difficult.

The mean MPOD value found by Beatty et al was $0.289 \pm 0.156,{ }^{19}$ which is lower than our mean value. This may also go some way to explaining the differences in repeatability and reproducibility coefficients, as we found a positive correlation between difference and mean MPOD values in our cohort. When limiting our analysis to subjects with MPOD of less than 0.35 , we found markedly different repeatability/reproducibility coefficients (JA1-JA2: $0.13, \mathrm{n}=13$; HB1-HB2: $0.24, \mathrm{n}=9$; JA1-HB1: $0.21, \mathrm{n}=11 ; \mathrm{HB} 2-\mathrm{JA2}: 0.15, \mathrm{n}=11)$. This suggests that the visual task is more difficult with higher MPOD levels, perhaps because of the higher intensity levels required to minimise flicker in these cases.

There have been no large-scale studies looking at the effect of $\mathrm{L}$ and $\mathrm{Z}$ supplementation in MPOD. The results of several small studies suggest that MPOD can be modified by nutritional supplementation and dietary modification, but only for some people. For example, MPOD increased by $4-5 \%$ in eight men supplemented with $10 \mathrm{mg}$ L daily. ${ }^{24}$ In another study an average increase in MPOD of $19 \%$ was found in people supplemented with spinach (providing $10.8 \mathrm{mg} \mathrm{L}$ and $0.3 \mathrm{mg} Z$ ) or sweetcorn (providing $0.4 \mathrm{mg} \mathrm{L}$ and $0.3 \mathrm{mg}$ Z) for up to 15 weeks, although three out of 13 participants were non-responders. ${ }^{25}$ Our results suggest that the MacuScope is not sensitive enough to identify changes in MPOD of this size. However, the coefficient of repeatability appears to be reduced for people with lower MPOD values. The manufacturers of the MacuScope classify 'low' MPOD as between 0.1 and 0.28 , 'average' MPOD as between 0.28 and 0.75 , and 'high' MPOD as between 0.75 and 1 . There were insufficient subjects in our cohort who measured within the 'low' (between one and five per comparison) or 'high' (either two or three per comparison) categories to allow viable sub-analysis.

The variability of the instrument might be improved if sensitivity to flicker was assessed for each subject prior to testing. This process is described by Snodderly et al, and ensures that the initial test conditions are set according to each subject's flicker sensitivity. ${ }^{17}$

The MacuScope macular pigment densitometer is a MPOD measurement device designed for use in clinical practice on naïve subjects. In conclusion, our results suggest that if MPOD is being monitored over time to assess the effect of an intervention, then any change less than 0.58 units should not be considered clinically significant as it is very likely to be due to instrument noise.

Acknowledgements The MacuScope was loaned to Aston University by Birmingham Optical Group, Birmingham, UK.

Contributors All named authors were involved in the conception and design of the study, analysis and interpretation of data, drafting the article and revising it critically for important intellectual content. All named authors gave final approval of the version published. HB and JA collected the data. FE provided training on data collection methods.

\section{Competing interests None.}

Ethics approval This study was conducted with the approval of the Aston University Human Ethics Committee.

\section{Patient consent Obtained.}

Provenance and peer review Not commissioned; externally peer reviewed.

\section{REFERENCES}

1. Wald G. Human vision and the spectrum. Science 1945;101:653-8.

2. Bone R, Landrum J, Tarsis S. Preliminary identification of the human macular pigment. Vision Res 1985;25:1531-5.

3. Krinsky NI. Possible biologic mechanisms for a protective role of xanthophylls. J Nutr 2002;132:540S-2.

4. Sommerburg 0, Siems W, Hurst J, et al. Lutein and zeaxanthin are associated with photoreceptors in the human retina. Curr Eye Res 1999;19:491-5.

5. Rapp LM, Maple SS, Choi JH. Lutein and zeaxanthin concentrations in rod outer segment membranes from perifoveal and peripheral human retina. Invest Ophthalmol Vis Sci 2000;41:1200-9.

6. Snodderly DM, Brown B, Delori F, et al. The macular pigment I. Absorbance spectra, localisation, and discrimination from other yellow pigments in primate retinas. Invest Ophthalmol Vis Sci 1984;25:660-73.

7. Pease P, Adams A, Nuccio E. Optical density of human macular pigment. Vision Res 1987;27:705-10.

8. Reading V, Weale R. Macular pigment and chromatic aberration. J Opt Soc Am 1974;64:231-8.

9. Malinow M, Feeney-Burns L, Peterson L, et al. Diet-related macular anomalies in monkeys. Invest Ophthalmol Vis Sci 1980;19:857-63.

10. Bailey F, Lovie-Kitchin J. New design principles for visual acuity letter charts. Am J Optom Physiol Opt 1976;53:745-53.

11. Bland J, Altman D. Statistical methods for assessing agreement between two methods of clinical measurement. Lancet 1986;1:307-10.

12. Elliott D, Sheridan M. The use of accurate visual acuity measurements in clinical anticataract formulation trials. Ophthalmic Physiol Opt 1988;8:397-401.

13. Ciulla TA, Curran-Celantano J, Cooper DA, et al. Macular pigment optical density in a midwestern sample. Ophthalmology 2001;108:730-7.

14. Ciulla TA, Hammond BR. Macular pigment density and aging, assessed in the normal elderly and those with cataracts and age-related macular degeneration. Am J Ophthalmol 2004;138:582-7.

15. Nolan J, O'Donovan 0 , Kavanagh $\mathrm{H}$, et al. Macular pigment and percentage of body fat. Invest Ophthalmol Vis Sci 2004;45:3940-50.

16. Richer S, Stiles W, Statkute L, et al. Double-masked, placebo-controlled, randomized trial of lutein and antioxidant supplementation in the intervention of atrophic agerelated macular degeneration: the Veterans LAST study (Lutein Antioxidant Supplementation Trial). Optometry 2004;75:216-30

17. Snodderly DM, Mares J, Wooten BR, et al. CAREDS Macular Pigment Study Group. Macular pigment measurement by heterochromic flicker photometry in older subjects: 
the carotenoids and age-related eye disease study. Invest Ophthalmol Vis Sci 2004; 45:531-8.

18. Moeller SM, Parekh N, Tinker $\mathrm{L}$, et al. Associations between intermediate agerelated macular degeneration and lutein and zeaxanthin in the carotenoids in agerelated eye disease study (CAREDS) - Ancillary study of the women's health initiative. Arch Ophthalmol 2006;124:1151-62.

19. Beatty S, Murray IJ, Henson DB, et al. Macular pigment and risk for age-related macular degeneration in subjects from a Northern European population. Invest Ophthalmol Vis Sci 2001:42:439-46.

20. Mares JA, LaRowe TL, Snodderly DM, et al. Predictors of optical density of lutein and zeaxanthin in retinas of older women in the Carotenoids in Age-Related Eye Disease Study, an ancillary study of the Women's Health Initiative. Am J Clin Nutr 2006;84:1107-22.
21. Hammond B, Caruso-Avery M. Macular pigment optical density in a Southwestern sample. Invest Ophthalmol Vis Sci 2000;41:1492-7.

22. Werner J, Donnelly S, Kliegl R. Aging and human macular pigment density: appended with translations from the work of Max Schultze and Ewald Hering. Vision Res 1987;27:257-68.

23. Bone R, Landrum JT, Fernandez L. Analysis of the macular pigment by HPLC: retinal distribution and age study. Invest Ophthalmol Vis Sci 1988;29:843-9.

24. Berendschot TT, Goldbohm RA, Klopping WA, et al. Influence of lutein supplementation on macular pigment, assessed with two objective techniques. Invest Ophthalmol Vis Sci 2000;41:3322-6.

25. Hammond BR Jr., Johnson EJ, Russell RM, et al. Dietary modification of human macular pigment density. Invest Ophthalmol Vis Sci 1997;38:1795-801. 